\title{
histórias
}

[ JOÃO BRAGA ]

Professor e estilista. Leciona nos cursos de graduação e pós-graduação de diversas escolas de moda, em São Paulo, as disciplinas História da Arte, História da Moda, Cultura de Moda e Estética. É autor dos livros História da moda: uma narrativa e Reflexões sobre moda, volumes I, II, III e IV. Com Luis André do Prado, é coautor de História da moda no Brasil: das influências às autorreferências.

\section{Cintura marcada: de marimbondo, de vespa ou de pilão?}

$[32]$

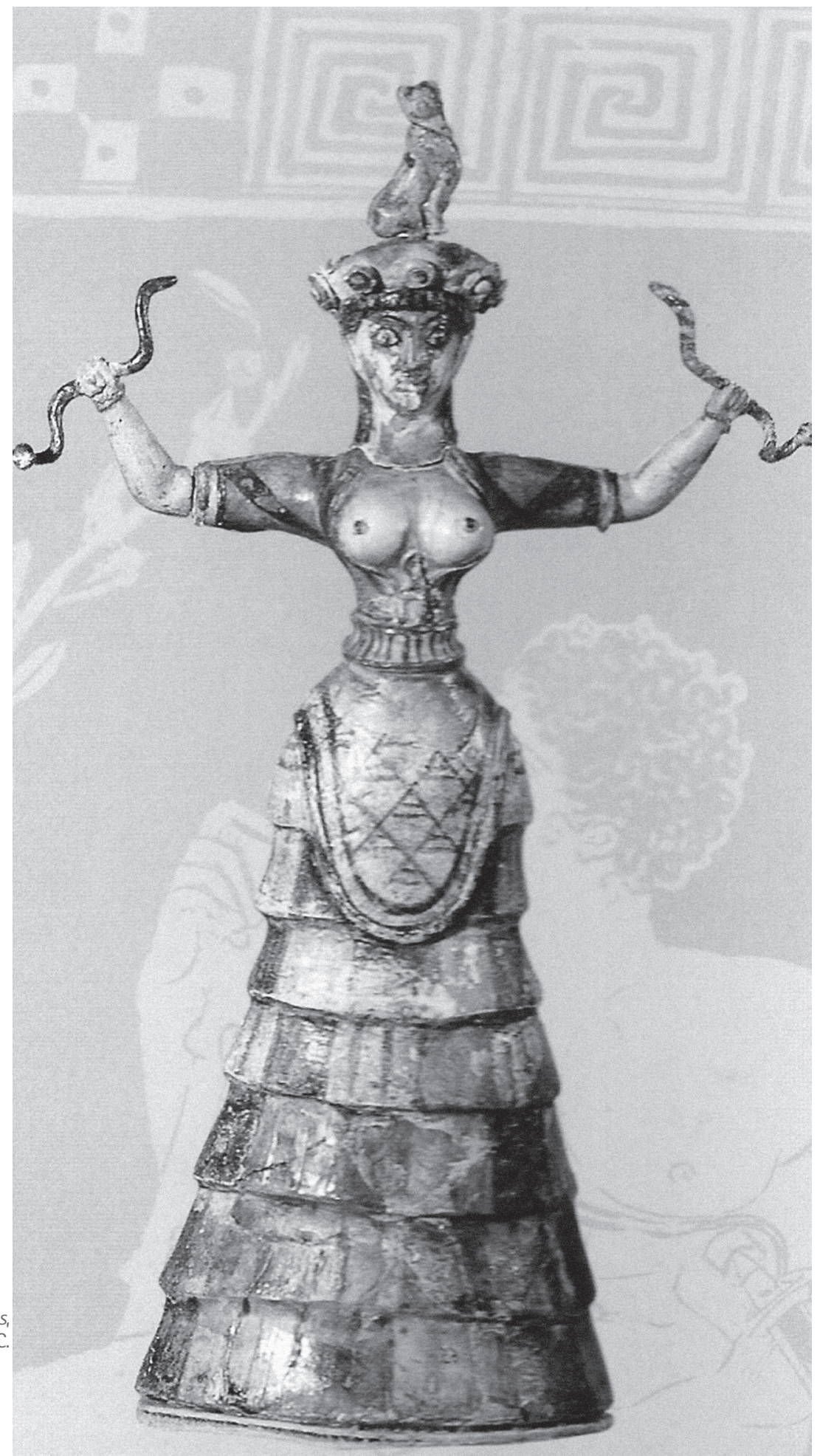


Evidenciar a cintura, ao longo dos tempos, vem sendo uma das identidades do universo dos vestíveis que esteve presente na História da Indumentária e da Moda. Seja por padrões estéticos associados à medida da proporção áurea, seja por questões de erotismo ou sedução, as mulheres, bem mais do que os homens, viveram e vivem utilizando deste recurso para valorizar suas formas naturais.

A palavra cintura, em língua portuguesa, deriva da palavra latina cinctura e passou a ser usada nas línguas neolatinas, em vernáculo, a partir do século XII. A origem está no substantivo cintus, que significa "maneira de se cingir, modo especial de cingir a toga", que vai nos dar, em português, cintura, cinto. Na forma verbal, deriva de cingo, que quer dizer cingir, cincundar, cercar, rodear com um cinto, envolver, revestir, que, no particípio passado do verbo, nos dá cinctus.

Cinctus também era um tipo de túnica ao tempo do Império Romano, cingida pelo meio do corpo e que chegava até aos pés; era também uma maneira de envolver-se na toga à maneira dos habitantes de Gábios, evidenciando parte do tronco ao redor da altura do umbigo, daí dando as palavras cintura, cinto.

Cingir-se marcadamente já foi voga inúmeras vezes entre as práticas de indumentária e/ou moda, e ainda usamos algumas expressões que nos são muito conhecidas, como "cintura de marimbondo", "silhueta ampulheta", "cintura de vespa", "cintura de pilão", "cintura de retrós", "cintura de tanajura", entre outras, para adjetivar a mulher cuja cintura é muito cingida, a ponto de acentuar e chamar atenção para essa parte do corpo.

Ao longo do processo historiográfico da indumentária e da moda, vale ressaltar alguns momentos nos quais a cintura foi evidenciada como padrão estético. Antes mesmo da cintura ligeiramente marcada no apogeu das culturas grega e romana, os habitantes da ilha de Creta, no Mediterrâneo, homens e mulheres, afunilavam (para não dizer estrangulavam) essa parte do corpo de tal maneira que ela se tornou uma das identidades visuais da indumentária desse povo, que teve o apogeu de sua cultura entre 1600-1450 a.C. Voltando à indumentária das duas culturas mais significativas da Antiguidade Clássica - Grécia e Roma -, esses povos também o fizeram, todavia de maneira mais sutil. Era comum usar algo ao redor da cintura, à semelhança de um cinto, para marcar as respectivas túnicas desses dois períodos.

Na Idade Média, não foi comum o hábito de marcar a cintura, talvez pela inexistência de intenções de erotismo nas roupas devido ao predomínio do pensamento teocêntrico. Pode-se até mesmo perceber, nesse intervalo de tempo, especificamente no período Gótico, o uso de certo tipo de cinto, em especial para os homens, que dava até mais de uma volta ao redor da cintura, cuja finalidade maior era pendurar um tipo de bolsinha chamada "esmoleira", na qual a pessoa levava alguns pertences de sua utilidade diária e também algumas moedas para doar a quem precisasse como prática de boa atitude cristã.

Em compensação, no período do Renascimento, as mulheres ousaram ao marcar suas cinturas quando da invenção do corpete. Essa peça, que pertencia à parte superior do vestido chamado "vertugado", chegava a ser até mesmo uma espécie de "engana olho", uma vez que a cintura era de tamanho relativamente normal, porém, externamente, havia um afunilamento tão acentuado que parecia ser uma seta apontando para o órgão sexual feminino, direcionando o olhar do observador para a região, além de dar à cintura a aparência de estar bem marcada. Nesse período, a mulher descobriu essa maneira de seduzir, percebendo que o afunilamento da cintura sensibiliza a percepção masculina. De lá para cá, foram só estratégias das mais ousadas para despertar a libido dos homens, tornando o recurso de marcar a cintura uma estratégia feminina de sedução.

Durante os períodos do Barroco e do Rococó, essa prática não foi diferente. $A$ cintura continuou sendo marcada pelo corpete, e, devido ao aumento do volume lateral da parte do vestido que corresponde à altura da saia, em especial no período do Rococó, tinha-se ideia da cintura ser mais afunilada ainda.

Já no início do século XIX, no período do Império, nada de cintura marcada à altura do umbigo. A marcação da cintura da roupa subiu até abaixo dos seios, transformando-se na famosa "cintura alta" ou "corte império". 
Com a mudança de pensamento e a consequente chegada do Romantismo, a partir da década de 1820, a cintura marcada na moda feminina voltou para a sua localização de origem, valorizada pelo uso de várias anáguas que aumentavam o volume da parte de baixo dos vestidos; e até mesmo o homem, numa postura dândi, chegou a marcar a cintura usando um tipo de corpete masculino ou os coletes bem mais justos. Com o passar do tempo, na Era Vitoriana, cada vez mais houve o afunilamento da cintura pelo uso do espartilho, atingindo exagero considerável no período seguinte: a Belle Époque - final do século XIX e início do século XX -, que tinha como ideal de beleza feminina uma cintura cujo perímetro devesse chegar em torno de $40 \mathrm{~cm}$ de circunferência. As mulheres mais ousadas chegaram a se submeter a cirurgia para serrar suas costelas flutuantes. Era a chamada "silhueta ampulheta" - a aparência feminina assemelhava-se a esse relógio de areia que tem a parte superior bojuda (correspondendo aos seios), o meio estrangulado (correspondendo à cintura) e a parte inferior também bojuda (correspondendo aos quadris). A então denominada "cinturinha de marimbondo" tornou-se o ideal de beleza feminina do período. Foi nesse momento histórico que essa parte do corpo da mulher teve o maior estrangulamento possivel, passando a ideia de uma mulher frágil e delicada que, visualmente, poderia "quebrar-se" ao meio.

Nos anos 1920, a cintura não ficou nada marcada, pelo contrário, deslocou-se para os quadris para deixar o corpo feminino à semelhança de um cilindro: é a "cintura baixa" ou "baixo quadril" dialogando com os traços geométricos predominantes na estética Art Déco. A década seguinte, dos anos 1930, já privilegiou a cintura mais acentuada, voltando a marcação do corpo feminino para a própria cintura. Durante a II Guerra Mundial, a moda feminina masculinizou-se, e, após o final da guerra, o francês Christian Dior, exatamente em fevereiro de 1947, retomou o padrão da cintura bem marcada, inspirando-se na silhueta das mulheres de fins do século XIX e resgatando a feminilidade na moda, e, com o "New Look", voltou a marcar a cintura da muIher. Sucesso total. Essa silhueta passou a ser o padrão de beleza da moda feminina nos anos 1950 e muitas vezes foi denominada de "cintura de vespa" ou "cinturinha de pilão", delineada pelo uso de apertadas cintas.

Na continuidade do processo histórico, a década de 1980 voltou a marcar a cintura da mulher pelo uso dos espartilhos, com a diferença de que as até então roupas de baixo do passado passaram a ser as roupas propriamente ditas. A cintura voltou a ser marcada, todavia sem os exageros pretéritos.

Com toda a evidência do glamour e da sofisticação presentes nas propostas contemporâneas da moda no século XXI, especialmente favorecidas pelas premissas dos aspectos de luxo e pela valorização da feminilidade, a cintura marcada volta à voga, sabendo, assim, a muIher que essa parte do corpo evidenciada aguça e sensibiliza o olhar masculino, tornando-se uma verdadeira estratégia de erotismo e sedução pelo viés da moda. 